\title{
Resonancia magnética de la endometriosis: Revisión pictográfica
}

Dres. Javiera Aguirre $F^{(1)}$, Cristian Medina $S^{(1)}$, Daniel Gaete $D^{(1)}$, Giancarlo Schiappacasse $F^{(2)}$, Pablo Soffia $S^{(3)}$.

1. Residente de Radiología, Facultad de Medicina Clínica Alemana - Universidad del Desarrollo. Santiago, Chile.

2. Profesor adjunto de Radiología, Clínica Alemana de Santiago. Facultad de Medicina Clínica Alemana-Universidad del Desarrollo. Santiago, Chile.

3. Profesor de Radiología, Clínica Alemana de Santiago. Facultad de Medicina Clínica Alemana - Universidad del Desarrollo. Santiago, Chile.

\section{MR imaging of pelvic endometriosis:A pictorial review}

\begin{abstract}
Endometriosis is the presence of endometrial tissue outside the uterine cavity ${ }^{(1-3)}$. This endometrial tissue may be located in the ovaries as endometriomas and/or as extraperitoneal/subperitoneal implants ${ }^{(3,4)}$. When implant depth is greater than $5 \mathrm{~mm}$, condition is referred to as deep endometriosis ${ }^{(3,4)}$. It represents a common cause of pelvic pain and infertility in young women(1-3). Surgery remains the best treatment option, so pre-operative evaluation to assess the extent of disease is essential(3,4).

Magnetic resonance imaging (MRI) is a non-invasive, non-ionizing radiation method, offering high contrast resolution, which allows multiplanar evaluation of endometriosis, thus facilitating a correct diagnosis and appropriate treatment ${ }^{(2-4)}$. Radiologists have to be familiar with MR imaging appearance of endometriosis, in order to guide clinicians and provide adequate information to assure accurate diagnosis and timely treatment of this entity.

Key words: Endometriosis, MRI.
\end{abstract}

Resumen: La endometriosis es la presencia de tejido endometrial fuera de la cavidad uterina ${ }^{(1-3)}$. El tejido endometrial puede localizarse en los ovarios como endometriomas y/o como implantes a nivel subperitoneal o extraperitoneal( ${ }^{(3,4)}$. Cuando estos implantes son mayores a $5 \mathrm{~mm}$ de profundidad, se denomina endometriosis profunda $^{(3,4)}$. Es una causa frecuente de algia pélvica e infertilidad en mujeres jóvenes ${ }^{(1-3)}$. La cirugía sigue siendo la mejor opción terapéutica por lo que la valoración preoperatoria de la extensión de la enfermedad es fundamental(3,4).

La resonancia magnética (RM) es un método no invasivo, sin el uso de radiación ionizante y con alta resolución de contraste, que permite la evaluación multiplanar de la endometriosis, facilitando así el diagnóstico correcto y el tratamiento adecuado ${ }^{(2-4)}$. Los radiólogos deben estar familiarizados con los hallazgos de imagen de RM de la endometriosis, a fin orientar al clínico y proporcionar información adecuada para el diagnóstico y tratamiento de esta patología.

Palabras clave: Endometriosis, RM.

Aguirre J, et al. Resonancia magnética de la endometriosis: Revisión pictográfica. Rev Chil Radiol 2012; 18(4): 149-156. Correspondencia: Dra. Javiera Aguirre Fernández / javiera.aguirre.fe@gmail.com

Trabajo premiado en el Congreso Chileno de Radiología 2012.

\section{Introducción}

La endometriosis es la presencia de tejido endometrial fuera de la cavidad uterina. Es una enfermedad estrógeno dependiente que afecta al $5-20 \%$ de las mujeres en edad reproductiva ${ }^{(1-3)}$. Se manifiesta como dispareunia, dismenorrea e infertilidad, aunque puede ser asintomática ${ }^{(1-3)}$.

El tejido endometrial ectópico puede localizarse en los ovarios como endometriomas y/o a nivel sub peritoneal como implantes en el tabique rectovaginal, en el ligamento útero-sacro, ligamento ancho, tracto gastrointestinal, sistema urinario y otros sitios extra-peritoneales como la pared abdominal ${ }^{(3-4)}$ (Figura 1). Cuando estos implantes son mayores a $5 \mathrm{~mm}$ de profundidad se denomina endometriosis profunda( ${ }^{(3-4)}$. 


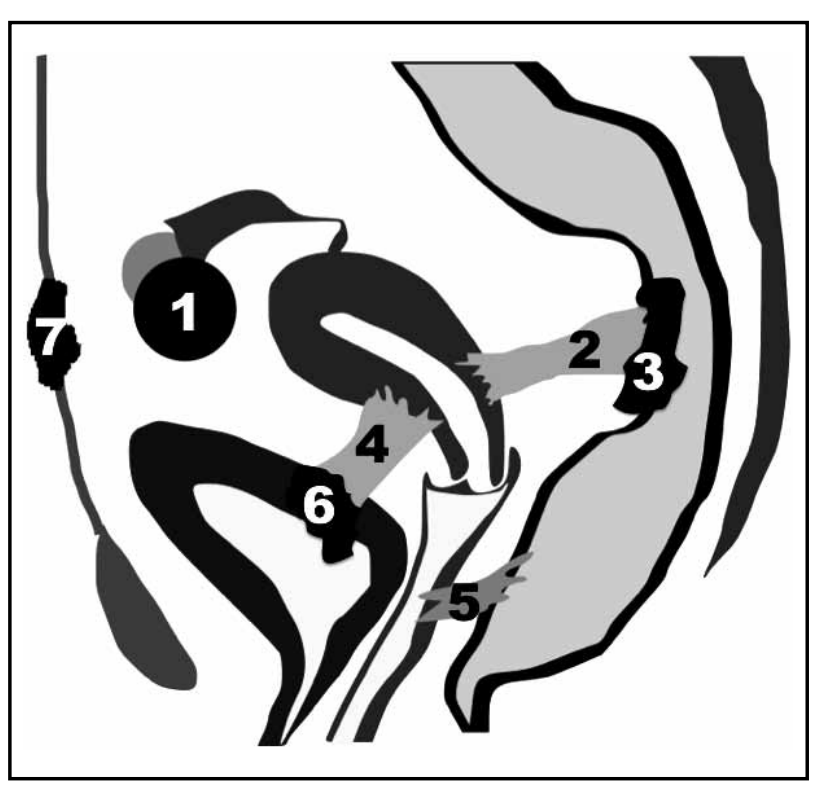

Figura 1. Principales localizaciones de Endometriosis. (1) Endometrioma ovárico, (2) Adherencias en el fondo de saco de Douglas, (3) Recto-Sigma, (4) Adherencias en el espacio vésico uterino, (5) Tabique recto vaginal, (6) Vejiga urinaria y (7) Pared abdominal.

\section{Etiología y patogenia}

Su etiología es multifactorial existiendo diversas teorías. La menstruación retrógrada es la más aceptada, con transporte de tejido endometrial desde la cavidad uterina hacia el peritoneo a través de las trompas $^{(1-3)}$.

Una segunda teoría sugiere que las células mesenquimales presentes en la superficie serosa (epitelio celómico) o tejido mülleriano remanente pueden diferenciarse hacia células endometriales ${ }^{(1-3)}$.

Una tercera teoría es la de la inducción, que es una combinación de las otras dos teorías. Sugiere que el endometrio secreta sustancias que inducen al mesénquima indiferenciado a formar tejido endometrial(2-3).

\section{Diagnóstico y técnicas de evaluación}

El diagnóstico y la evaluación de la endometriosis están limitados para la exploración física ${ }^{(3-5)}$. La laparoscopía es la técnica estándar para el diagnóstico de la endometriosis ${ }^{(4-5)}$, siendo patognomónicas las lesiones nodulares de color marrón o negro en las superficies peritoneales ${ }^{(5)}$, sin embargo, no visualiza las lesiones ocultas por adherencias y no identifica las lesiones atípicas (no pigmentadas) ${ }^{(5)}$. La ecografía es por lo general la primera técnica de imagen y la más comúnmente utilizada para la evaluación de pacientes con síntomas pélvicos e infertilidad ${ }^{(5)}$. Es un buen método para la detección de masas anexiales con la apariencia de endometriomas ${ }^{(2-5)}$, sin embargo, no puede diferenciar algunos endometriomas de quistes hemorrágicos $u$ otras neoplasias de ovario y no es sensible en la detección de los implantes peritonea-

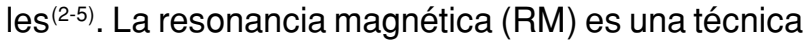
de imagen no invasiva, sin el uso de radiaciones ionizantes o agentes de contraste yodados ${ }^{(3)}$. La RM es un excelente método para identificar el contenido hemorrágico antiguo que caracteriza a los endometriomas $^{(5)}$ y permite la identificación de los implantes sub-peritoneales e implantes ocultos por las adherencias, dada su gran campo de visión, la capacidad multiplanar y su alta resolución de contraste ${ }^{(4,5)}$. Se ha estimado que su sensibilidad, especificidad y exactitud es del $90 \%, 98 \%$ y $96 \%$, respectivamente, para el diagnóstico de endometriomas y en la diferenciación de otros masas ginecológicas ${ }^{(5)}$.

\section{Técnica de resonancia magnética Preparación del paciente}

Las imágenes se obtienen de forma independiente al ciclo menstrual, la paciente se debe presentar en ayunas de al menos 4-6 horas y abstenerse de la micción durante 1 hora antes del examen. Esto corrige el ángulo de anteversión uterina y desplaza a cefálico el intestino delgado. El día anterior al examen se puede realizar limpieza intestinal con un laxante oral.

En la mayoría de los casos se aplica $50-60 \mathrm{ml}$ de gel de ultrasonido endovaginal para distender la cavidad vaginal y permitir una mejor evaluación de la zona retrocervical y fondos de saco vaginales. Sólo en casos de sospecha de compromiso rectal se aplican $60 \mathrm{ml}$ de gel de ultrasonido endorectal.

En aquellos casos en que las primeras imágenes muestran degradación por artefactos de perístasis intestinal, se recomienda inyectar Buscapina $10 \mathrm{mg}$ intravenosa.

\section{Obtención de imágenes}

En nuestra institución se utilizan resonadores magnéticos de 1.5 T (General Electric Medical Systems) y de $3 \mathrm{~T}$ (Siemens Medical Solutions), utilizando secuencias multiplanares axiales, sagitales y coronales potenciadas en T2 FSE y secuencias axiales potenciadas en T1 SE sin y con supresión grasa pre contraste.

También se obtienen imágenes axiales y/o sagitales después de la inyección intravenosa de contrastes basado en gadolinio.

\section{Características imagenológicas de la endometriosis}

Las principales manifestaciones de la endometriosis son quistes ováricos de contenido hemorrágico (endometriomas), nódulos fibróticos y adherencias sub-peritoneales y en otras localizaciones ${ }^{(1-3)}$, cada una de las cuales tiene características en RM que se detallan a continuación, agrupando los principales hallazgos en; (A) Endometriomas ovarios, (B) Endometriosis profunda pelviana y (C) Endometriosis profunda extra-peritoneal. 


\section{A. Endometriomas}

Los endometriomas son quistes que se producen en los ovarios, siendo el resultado de la hemorragia cíclica y repetida. Tienen paredes gruesas y su contenido es oscuro por degeneración de los productos sanguíneos. Este aspecto ha sido llamado "quiste de chocolate"(2-4). Son bilaterales hasta en la mitad de los casos. Aunque suelen ser grandes, sin embargo, rara vez superan los $15 \mathrm{~cm}$ de diámetro ${ }^{(2-4)}$.

Los endometriomas ováricos (Caso №1), son típicamente hiperintensos en secuencias potenciadas en $\left.T 1^{(2,4,5}\right)$. Esta hiperintensidad es más evidente en las imágenes realizadas en T1 con supresión grasa, ya que se elimina la señal alta de la grasa circundante, aumentando así la sensibilidad para la detección de pequeños focos de endometriosis ${ }^{(2,4,5)}$. Mientras que en secuencias potenciadas en T2 son hipointensos, efecto denominado sombreado o "shading"(3-5), que se explica por la presencia de sangre en distintos estadios $^{(2)}$. El uso de gadolinio puede mostrar un patrón de realce no específico y variable que no diferencian de otros procesos benignos y malignos ${ }^{(2)}$.

\section{B. Endometrosis profunda peritoneal}

La endometriosis profunda corresponde a los
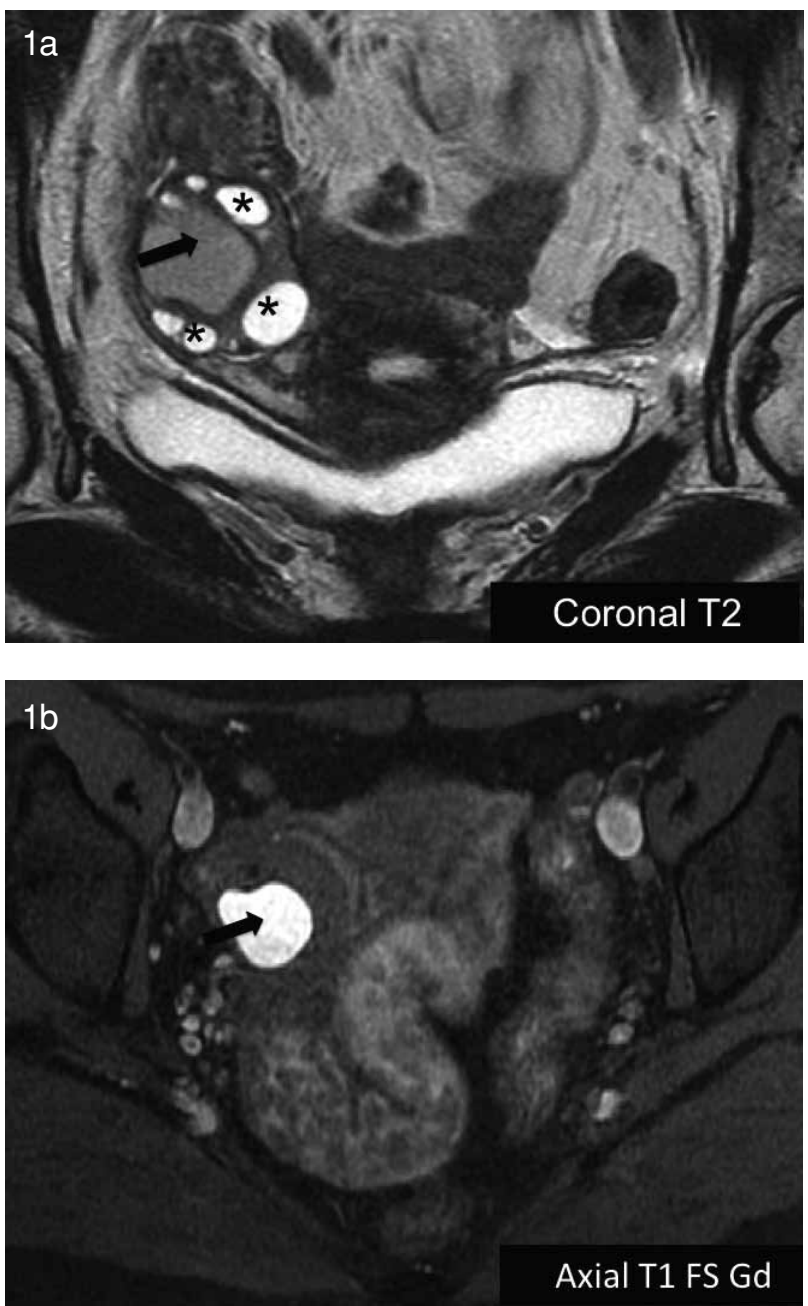

implantes de más de $5 \mathrm{~mm}$ de profundidad.

A diferencia de los endometriomas, los implantes de endometriosis profunda pueden tener características diferentes en la imagen de RM. La mayoría de éstos son hipointensos en secuencias potenciadas en $\mathrm{T} 2$ como en $\mathrm{T} 1^{(1-3)}$. Esta hipointensidad es debida a una reacción desmoplásica con proliferación fibromuscular ${ }^{(1-3)}$. Presentan bordes mal definidos de aspecto infiltrante, produciendo retracción de órganos o estructuras vecinas ${ }^{(1-3)}$.

La presencia de focos hemorrágicos, hiperintensos en secuencias T1 sin y con supresión de la grasa, es un hallazgo de RM muy característico de los implantes endometriósicos, pero se ve con menor frecuencia en los implantes profundos que en las lesiones anexiales ${ }^{(1-3)}$.

Los implantes pueden realzar con gadolinio, sin embargo esta característica no es sensible ni específica $^{(2)}$.

Los implantes a nivel de la pelvis pueden ser clasificados según el compartimiento afectado(3) $^{(3)}$ (Figura 2).

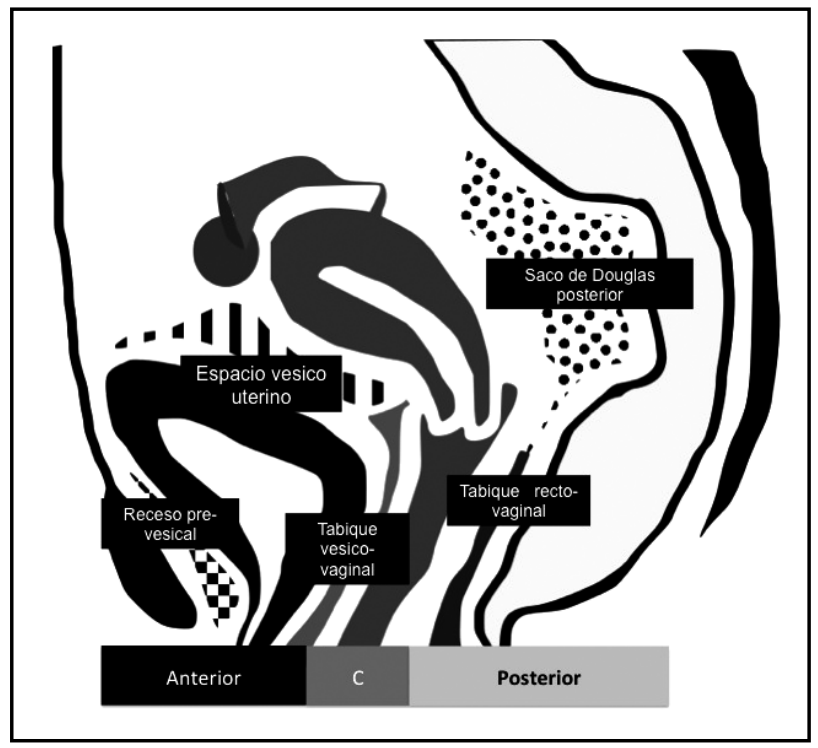

Figura 2. Compartimientos de la pelvis. Anterior: Espacio virtual situado entre la cara anterior del útero y la pared posterior vesical, incluye a la vejiga urinaria, uretra, el espacio vésico uterino y el tabique vésico vaginal. Central: Entre el compartimiento anterior y posterior, incluye el útero, trompas, ovarios y ligamento ancho. Posterior: Espacio virtual situado entre la cara posterior del cérvix-vagina y la pared anterior rectal, incluye el tabique recto vaginal, ligamentos úterosacros, torus uterino, fondo de saco de Douglas y recto-sigma.

Caso № 1. Mujer de 37 años con historia de dismenorrea. Imágenes: (a) coronal potenciada en T2 y (b) axial T1 con supresión grasa y gadolinio. Ovario derecho aumentado de tamaño con múltiples quistes $\left(^{*}\right)$ y un endometrioma de señal intermedia en T2 e hiperintenso en T1 con supresión grasa y gadolinio (Flecha negra). 


\section{Clasificación según localización pelviana de la endometriosis profunda}

\section{B. 1.Compartimiento anterior}

Este compartimiento incluye implantes que se localizan en el fondo vésico-uterino, tabique vésicovaginal, vejiga (musculo detrusor) y uréteres ${ }^{(3)}$.

Son lesiones menos frecuentes y hasta en un $75 \%$ se asocian a lesiones de otros compartimientos ${ }^{(3)}$. La endometriosis del tracto urinario se produce en aproximadamente el $20 \%$ de los casos y la vejiga es el órgano más frecuentemente afectado(4), seguido por los uréteres ${ }^{(2)}$. Cuando hay afectación vesical, los implantes de endometriosis a menudo se limitan a la superficie serosa, sin embargo, también pueden infiltrar la capa muscular hasta proyectarse en el lumen vesical(3). En la mayoría de los casos, los implantes del lumen vesical son iatrogénicos en relación a cirugía pelviana ${ }^{(3)}$. Estos pueden manifestarse clínicamente como hematuria cíclica (Caso №2).
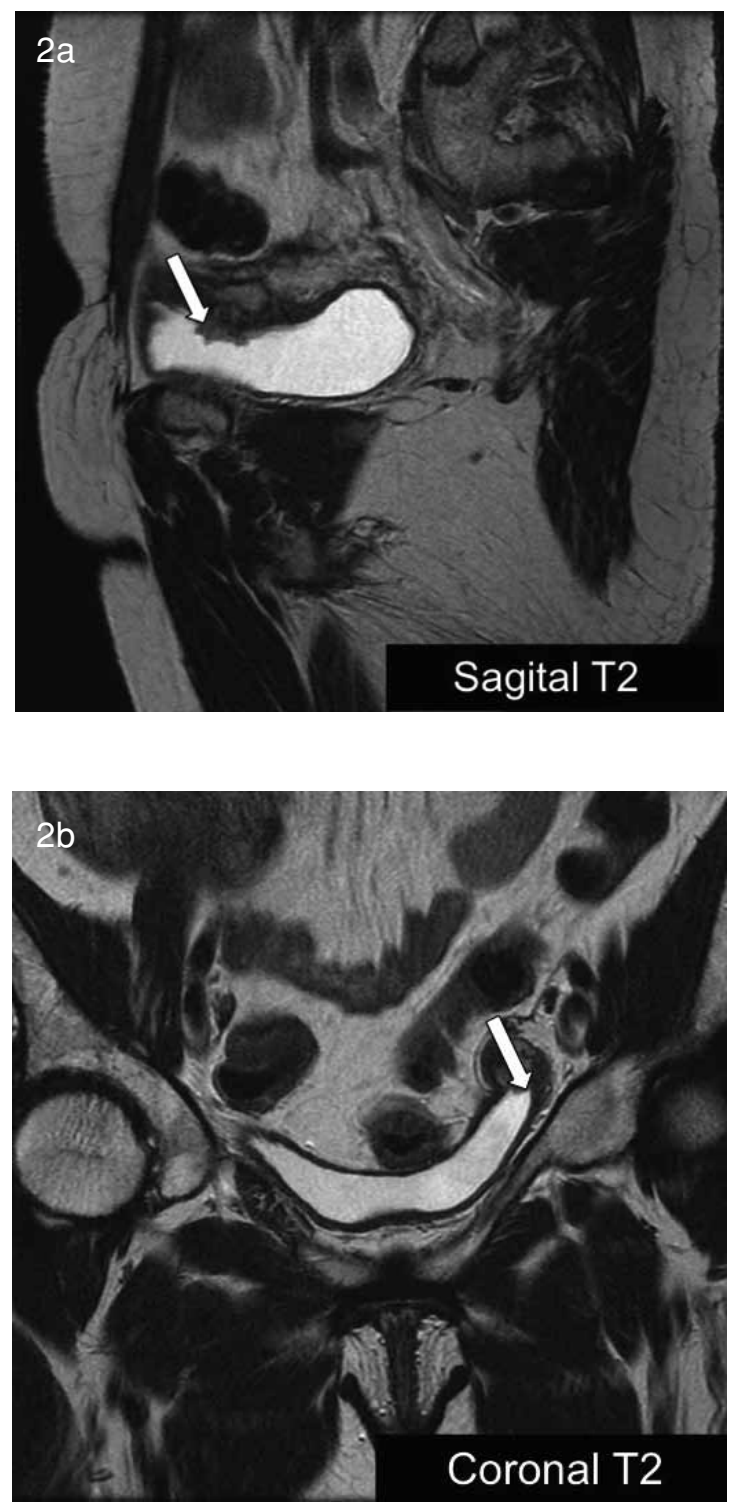
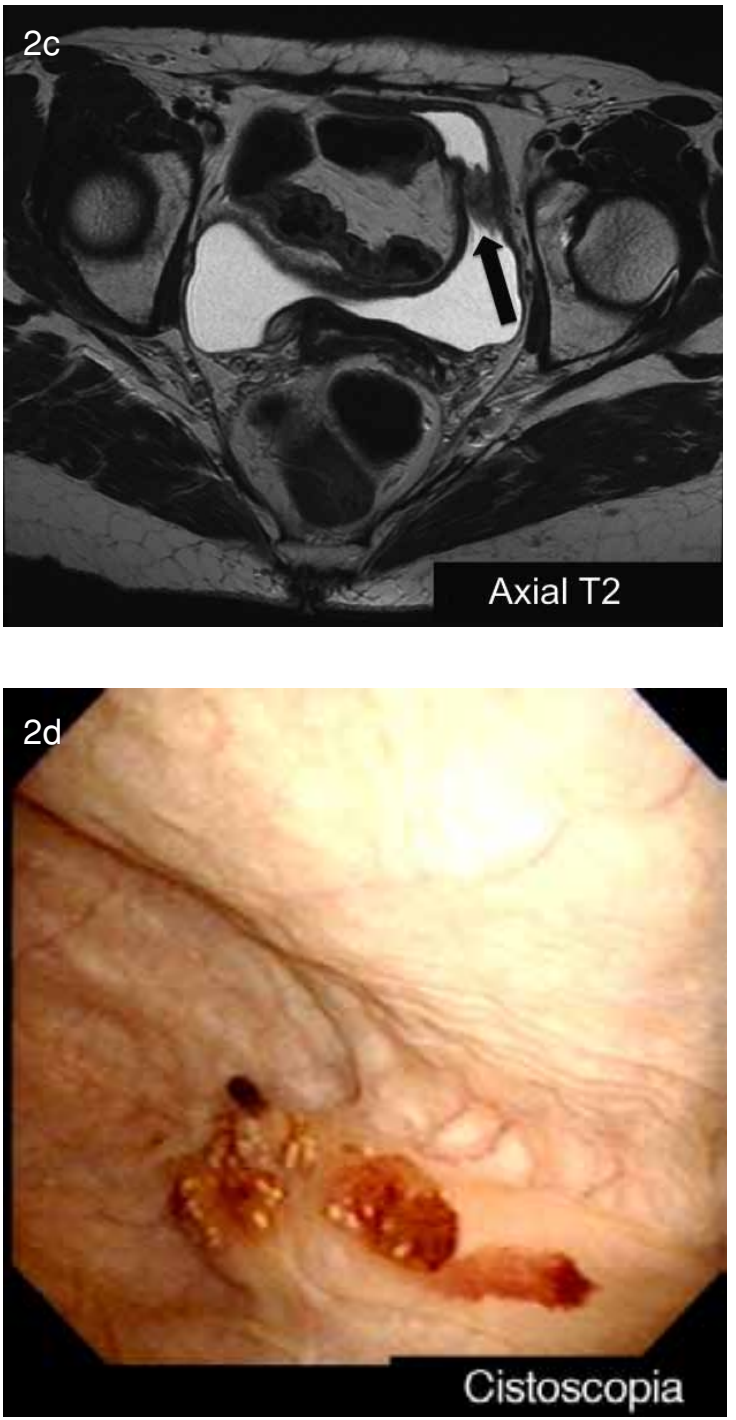

Caso № 2. Mujer de 53 años. Antecedentes de histerectomía con historia de hematuria cíclica. Imágenes: (a) Sagital potenciada en T2, (b) Coronal T2, (c) Axial T2 y (d) Cistoscopia. En el techo vesical a izquierda (Flecha blanca) se observa una masa de 1,5 × 1,1 cm, ésta es de señal intermedia $T 2$ de bordes mal definidos que infiltra la pared vesical, localizándose en el lumen vesical (Flecha negra). En la cistoscopia se observa, en la pared superior izquierda, una lesión solevantada sésil de aproximadamente $1 \mathrm{~cm}$. El resto de la mucosa vesical se ve de aspecto normal $y$ sin lesiones.

En la afectación ureteral (Caso №3) el tejido endometriósico se implanta en la adventicia ureteral, la invasión directa del uréter puede provocar hiperplasia y fibrosis de la muscular propia, lo que resulta en estrechamiento luminal(2-3). Esto se puede manifestar como hidroureteronefrosis y en casos más severos, como falla renal(3). El deterioro de la función renal se puede observar en hasta un 30\% de estos $\operatorname{casos}^{(3)}$. 

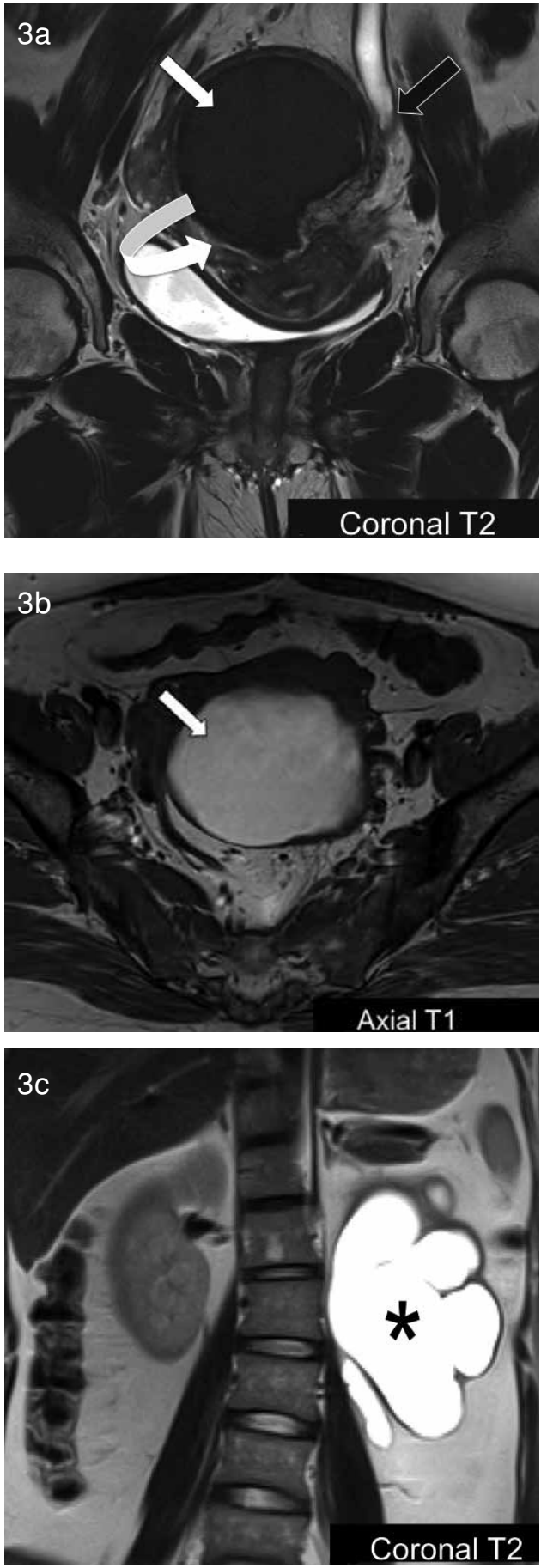

Caso № 3. Mujer de 31 años con historia dismenorrea. Imágenes: (a) coronal potenciada en T2, (b) axial T1 y (c) coronal T2. Endometrioma ovárico izquierdo (Flecha blanca) de 9,3x7,6 cm adherido al torus uterino por un foco de endometriosis profunda. (Flecha blanca curva). Infiltración del uréter distal por implante fibrótico endometrial (Flecha) que es asociado a hidroureteronefrosis(*).

\section{B. 2. Compartimiento central}

El compartimento central contiene los órganos genitales femeninos, como los ovarios, las trompas uterinas, útero y vagina. Incluye también los ligamentos anchos que son pliegues peritoneales entre el útero y las paredes laterales de la pelvis y los ligamentos redondos del útero(3).

La afectación más frecuente en este compartimiento es a nivel de los ovarios como endometriomas, ya comentado anteriormente, aunque también puede observarse implantes fibróticos en los ovarios ${ }^{(3)}$.

Los ligamentos uterinos (ligamentos anchos y redondos del útero), pueden verse afectados, observándose engrosamiento y nodularidad de estas estructuras ${ }^{(3,4)}$.

La participación de las trompas de Falopio por lo general ocurre en la capa sub-serosa(3) y está fuertemente asociada con la infertilidad ${ }^{(3)}$ (Caso №4).
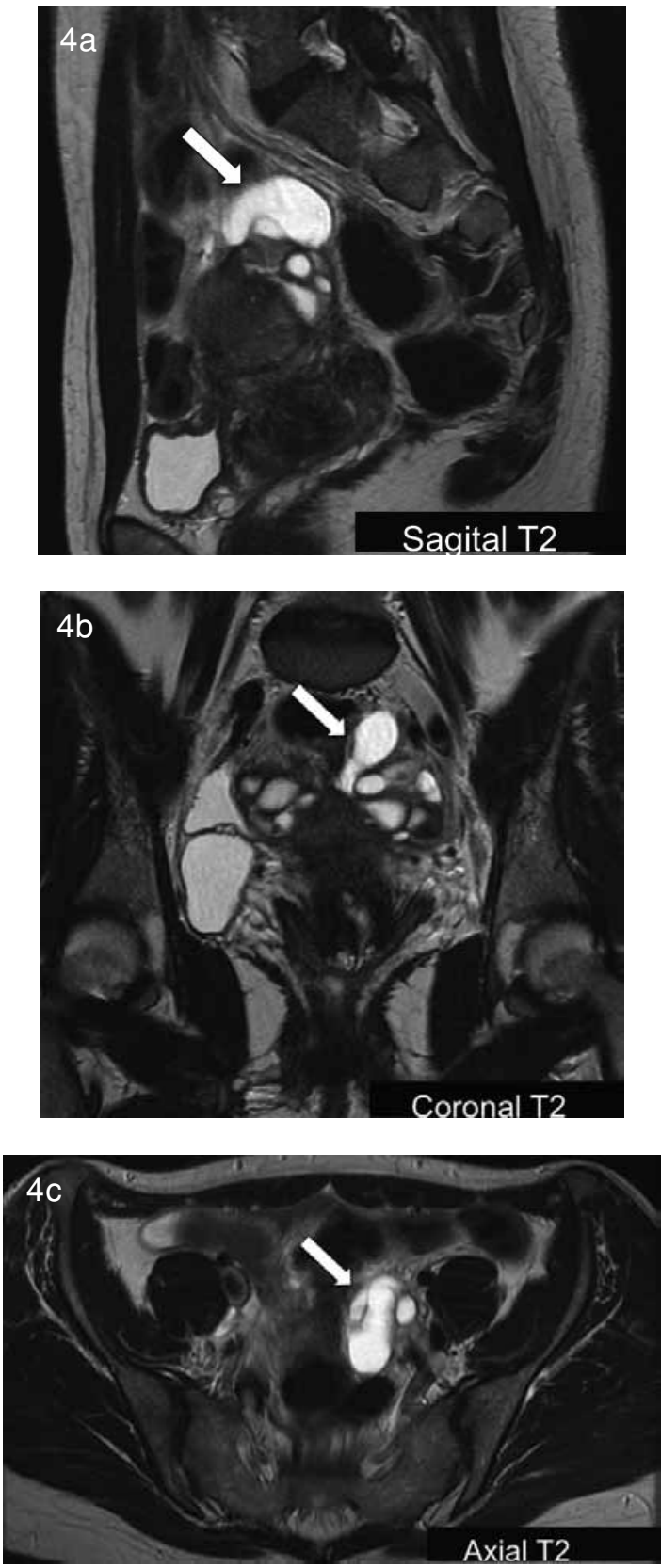

Caso № 4. Mujer de 37 años. Estudio de infertilidad. Imágenes: (a) sagital potenciada en T2 y (b) coronal T2 y (c) axial T2. Endometriomas ováricos bilaterales e hidrosálpinx izquierdo (Flecha blanca). 


\section{B. 3. Compartimiento posterior}

Espacio virtual situado entre la cara posterior del cérvix-vagina y la pared anterior rectal, incluye al tabique recto vaginal, ligamentos útero-sacros, torus uterino, fondo de saco de Douglas y rectosigma ${ }^{(3)}$. Es la localización más frecuente, siendo el espacio retrocervical y el torus uterino (que corresponde a la reflexión del peritoneo sobre el fondo uterino) los sitios más afectados ${ }^{(3)}$. Suelen producir adherencias peritoneales y retracción de los ovarios hacia la parte póstero-central ubicándose adyacentes entre sí, signo radiológico denominado ovarios en beso o "kissing ovaries"(6) (Caso №5).

El tracto gastro intestinal puede estar comprometido en un $12-37 \%$ de los pacientes con endometriosis ${ }^{(2-4)}$. Afecta más comúnmente a los
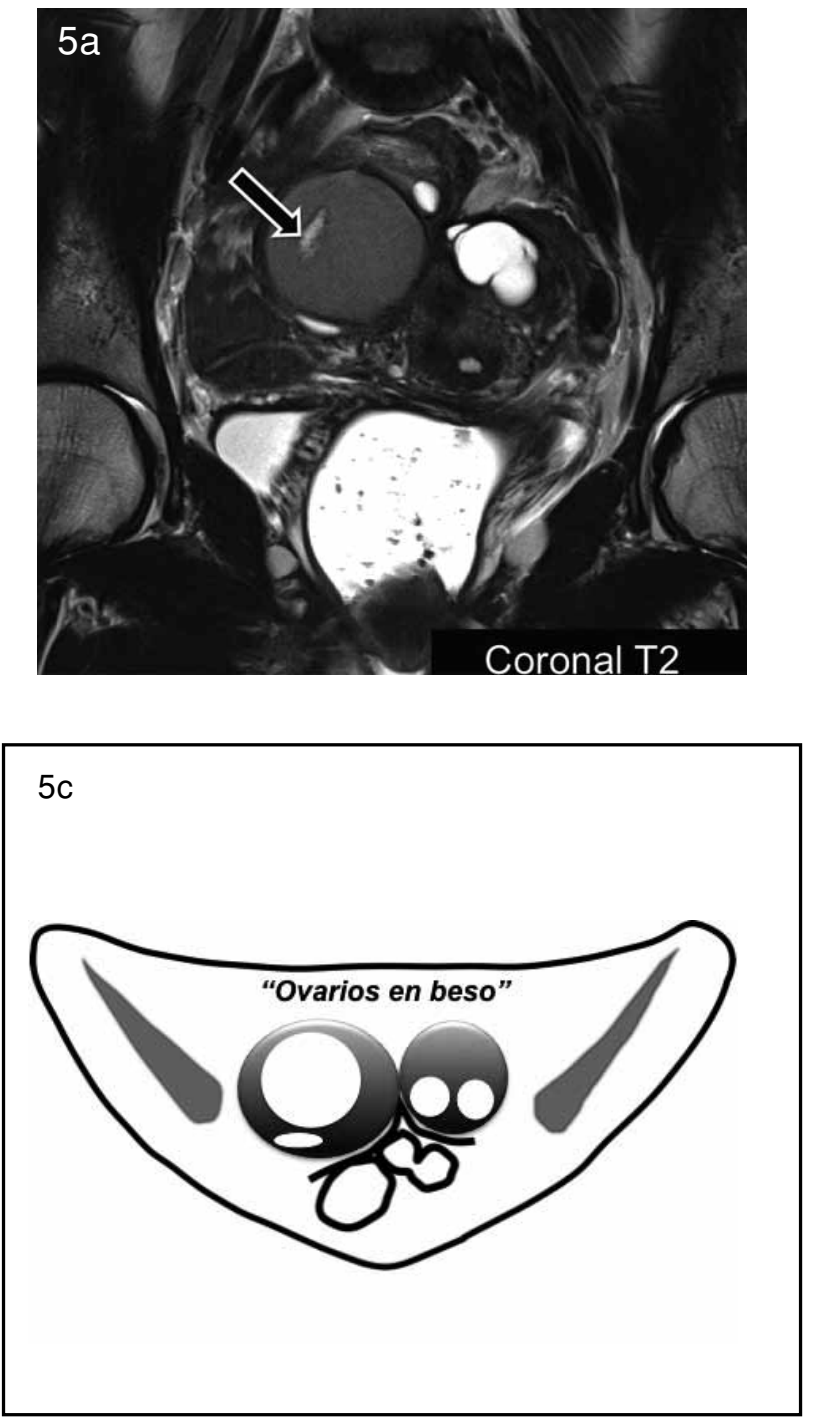

segmentos del intestino en la parte dependiente de la pelvis y raramente se encuentra proximal al íleon terminal(2). Las zonas más comúnmente afectadas en orden decreciente de frecuencia son el colon sigmoides, apéndice, ciego e íleon distal(2). Los implantes suelen localizarse en la superficie serosa, pero eventualmente puede erosionar las capas sub serosas y causar marcado engrosamiento y fibrosis de la muscular propia hasta llegar a invadir la mucosa ${ }^{(2-4)}$. La invasión del colon sigmoides o recto puede causar rectorragia catamenial y alteraciones del tránsito. En los casos de invasión del recto, éstos pueden adoptar una morfología descrita en la literatura como el signo de la cubierta de hongo o "mushroom cap sign"(7) (Caso №6).
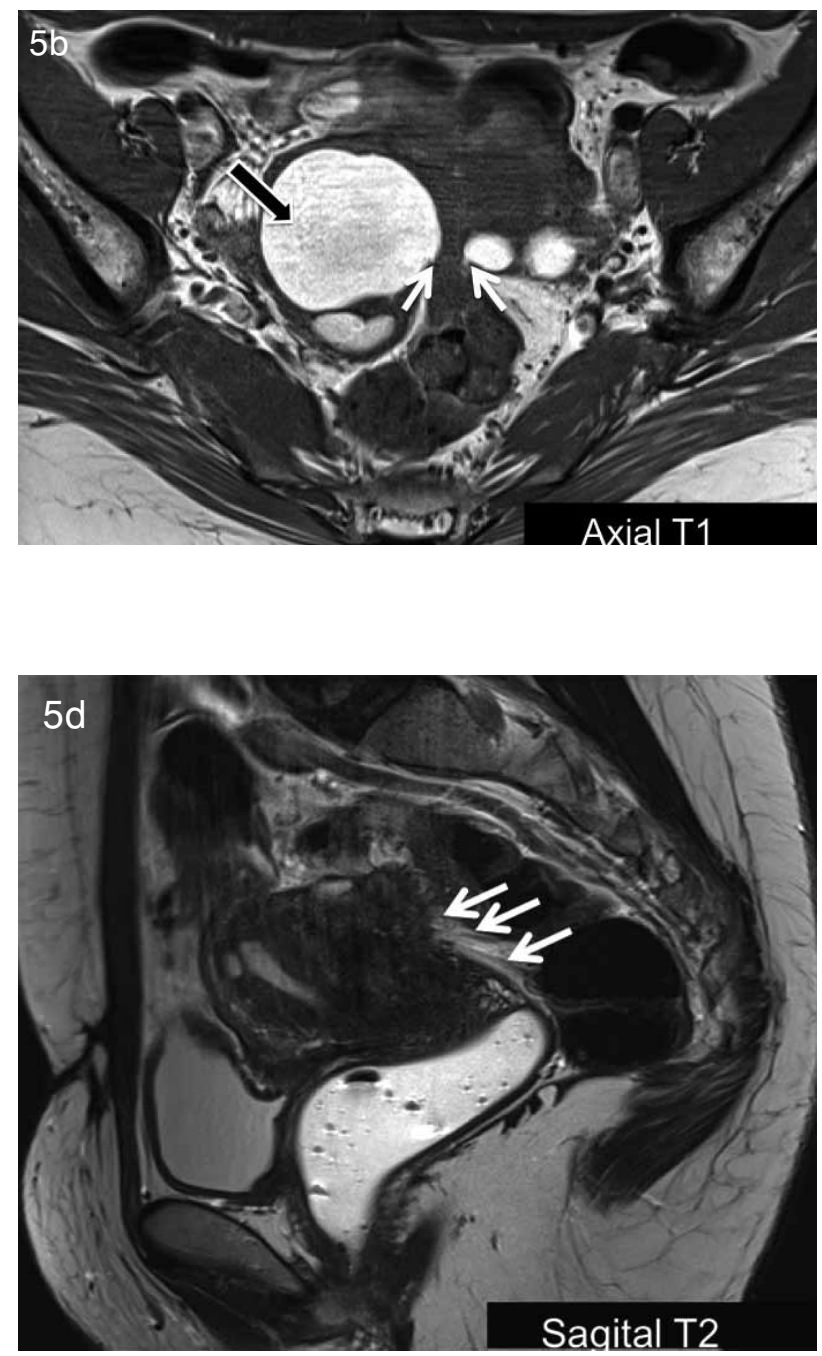

Caso №5. Mujer de 32 años. Historia de dismenorrea e infertilidad. Imágenes: (a)coronal ponderada en T2 ,(b) axial $T 1$, (c) representación gráfica de b y (d) sagital T2. Ovarios aumentados de tamaño con endometriomas (Flecha negra) y quistes. Éstos se encuentran adyacentes entre sí, signo conocido como ovarios en beso o "kissing ovaries". Endometriosis profunda fibrosa del fondo de saco de Douglas con adherencia del útero-unión rectosigmoidea y ovarios (Flechas blancas). 


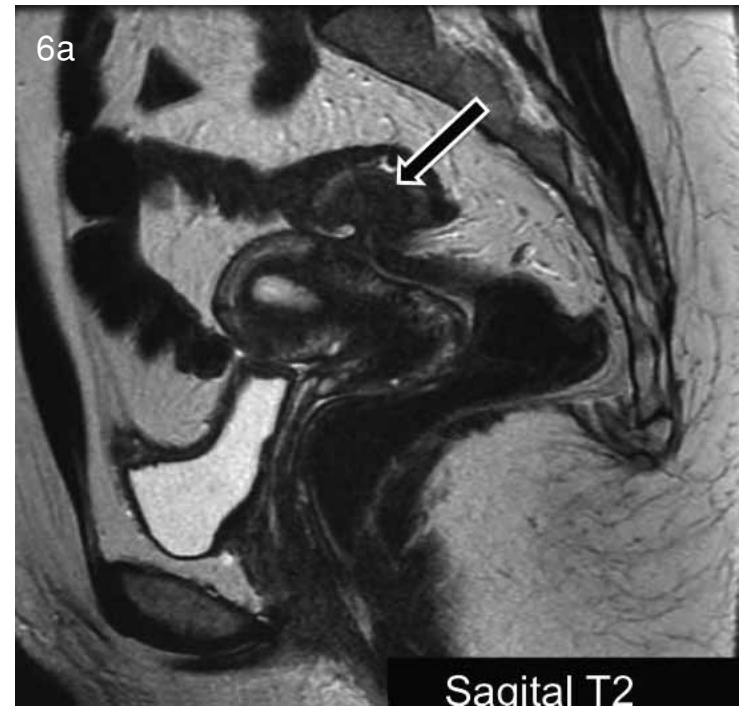

$6 b$

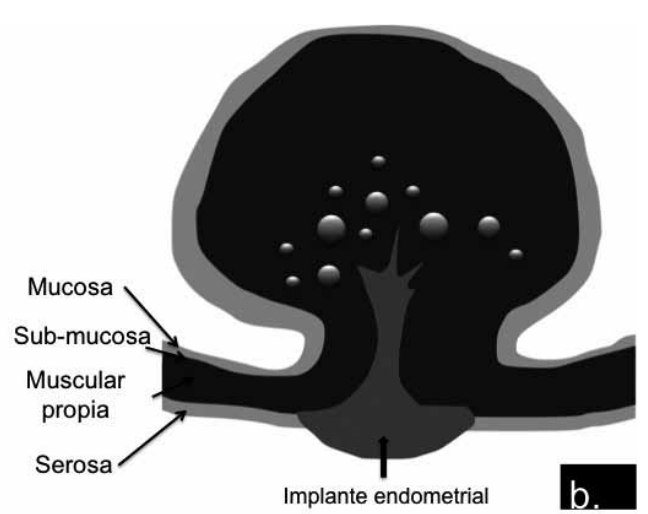

Caso № 6. Mujer de 34 años. Historia de rectorragia asociada a menstruación. Imágenes: (a) sagital potenciada en T2 y (b) representación gráfica del implante endometrial invadiendo las paredes rectales. Endometriosis profunda fibrosa en fondo uterino invadiendo la pared rectal, con signo de cubierta de hongo o "Mushroom cap sing", hipointensa en T2 (Flecha negra).

\section{Endometriosis extraperitoneal}

Corresponden a todos los implantes localizados fuera de la cavidad peritoneal. Se han descritos implantes en la cavidad torácica, en la pared abdominal y pelviana(2).

La pared abdominal es el sitio más frecuente de endometriosis extraperitoneal. La de mayoría de los implantes se localizan cercanos a cicatrices de cesáreas previas ${ }^{(8)}$ (Caso №7). Estos implantes pueden ubicarse a nivel muscular sub-cutáneo o ambos.

Su características en RM es variable, pero la mayoría son iso o hipointensos en $\mathrm{T} 1$ y $\mathrm{T} 2^{(8)}$.

Otro sitio de localización es la episiorrafia (caso №8). Se puede manifestar con un nódulo palpable en la región perianal con cambios cíclicos de tamaño( ${ }^{(8)}$.
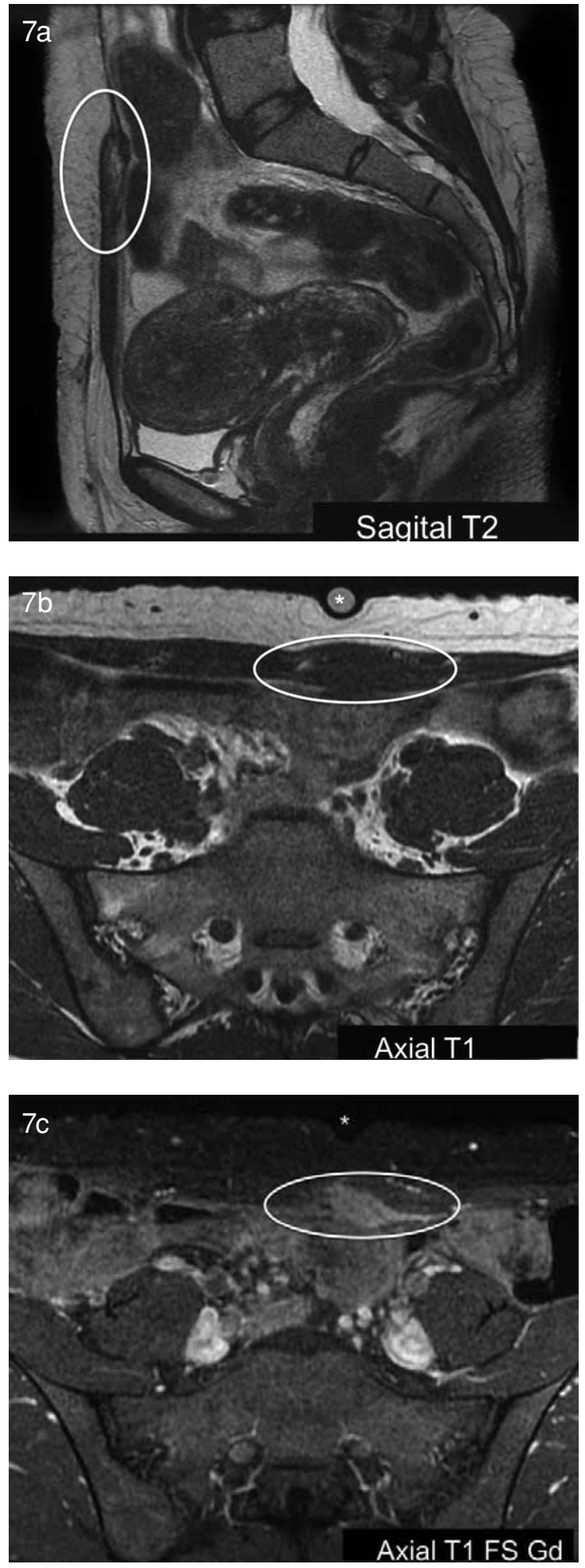

Caso № 7. Mujer de 46 años. Nódulo de la pared abdominal en estudio.

Imágenes: (a) sagital ponderada en T2 y (b) axiales T1 y (c) axial T1 con supresión grasa y gadolinio. Nódulo sólido de $20 \times 12 \mathrm{~mm}$ en pared abdominal a nivel del hipogastrio lateralizado a izquierda, de señal heterogénea (con focos hipointensos) en T2 e isointenso en T1 (círculo blanco) con realce discreto y homogéneo con contraste. Marcador externo $\left({ }^{*}\right)$. Se reseca el nódulo y la histología fue compatible con foco de endometriosis. 

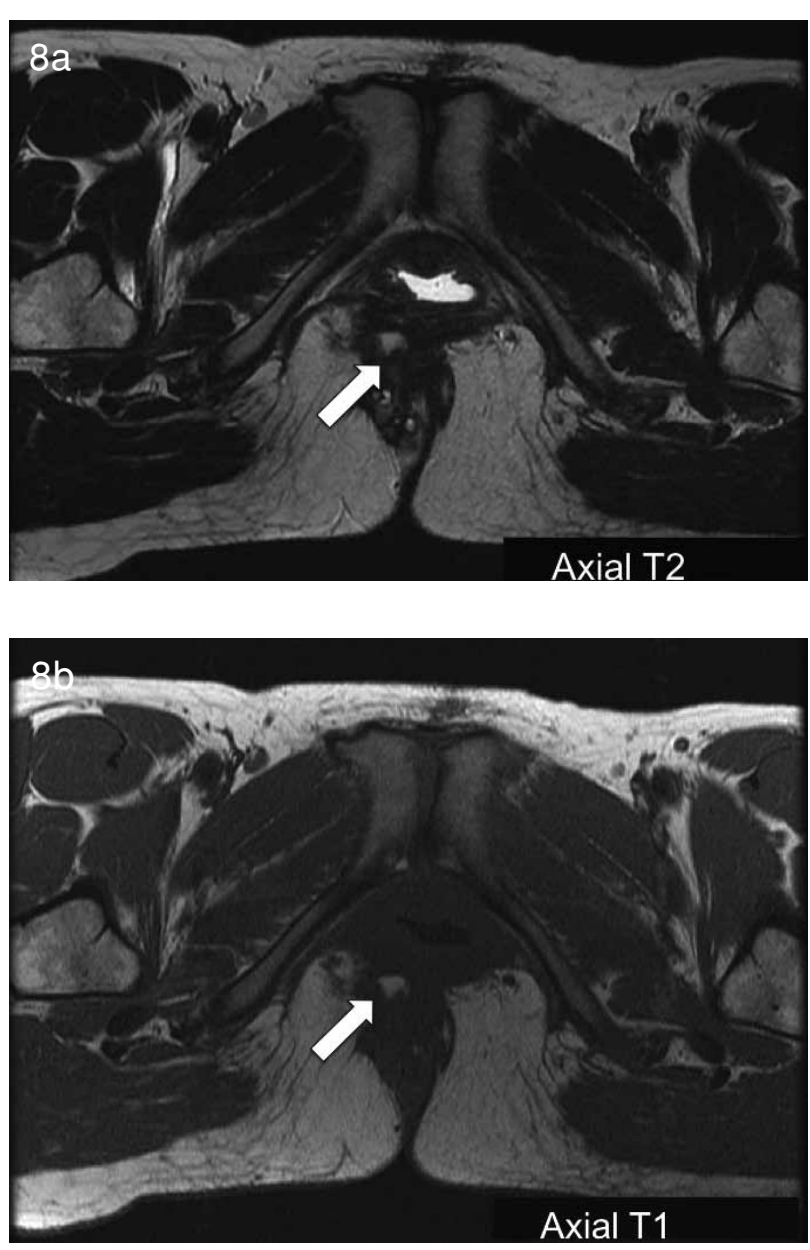

Caso № 8. Mujer de 33 años. Nódulo palpable en relación a episiorrafia.

Imágenes: (a) axial ponderada en T2 y (b) axial T1. Nódulo lobulado en la región perianal derecha en sitio de episiorrafia (Flecha blanca). Levemente hiperintenso en T1 e isointenso en T2.

\section{Conclusión}

La endometriosis es una causa frecuente de algia pélvica e infertilidad en mujeres jóvenes ${ }^{(1-3)}$. La cirugía sigue siendo la mejor opción terapéutica ${ }^{(3,4)}$. El tratamiento exitoso requiere de la eliminación de la lesión con cirugía radical. La valoración precisa preoperatoria de la extensión de la enfermedad es extremadamente importante ${ }^{(3,4)}$. La exploración física por sí sola no proporciona información preoperatoria adecuada $^{(3,4)}$.

La ecografía es la técnica de imagen más usada ante su sospecha, sin embargo es inespecífica y se limita a la evaluación de endometriomas ${ }^{(2-5)}$. Por el contrario, la RM proporciona un diagnóstico más preciso y específico de los endometriomas, y una mejor caracterización de la endometriosis profunda, presentando morfología y alteración de la señal características. También la RM es capaz de evaluar lesiones ocultas por densas adherencias, las cuales no son visibles en la laparoscopía ${ }^{(2-4)}$. Los radiólogos deben estar familiarizados con los hallazgos de imagen de RM de la endometriosis, a fin orientar y proporcionar información adecuada para el diagnóstico y tratamiento de esta patología.

\section{Bibliografía}

1. Jan-Hein J. Hensen and Julien BCM. Puylaert. Endometriosis of the Posterior Cul-De-Sac: Clinical Presentation and Findings at Transvaginal Ultrasound. Am. J. Roentgenol 2009; 192: 1618-1624.

2. Woodward PJ, Sohaey R, Mezzetti TP. Endometriosis: radiologic-pathologic correlation. RadioGraphics 2001; 21: 193-216.

3. Coutinho A Jr., Bittencourt LK, Pires CE, et al. MR imaging in deep pelvic endometriosis: a pictorial essay. RadioGraphics 2011; 31(2): 549-567.

4. Chamié LP, Blasbalg R, Pereira RM, Warmbrand G, Serafini PC. Findings of pelvic endometriosis at transvaginal US, MR imaging, and laparoscopy. RadioGraphics 2011; 31(4): E77-E100.

5. Bennett GL, Slywotzky CM, Cantera M, Hecht EM. Unusual manifestations and complications of endometriosis-spectrum of imaging findings: pictorial review. AJR Am J Roentgenol 2010; 194(6 suppl): WS34-WS46.

6. Penelope L. Moyle, Masako Y. Kataoka, Asako Nakai, Akiko Takahata, Caroline Reinhold, and Evis Sala. Nonovarian Cystic Lesions of the Pelvis. Radiographics 2010; 30(4); 921-938.

7. Yoon JH, Choi D, Jang KT, Kim CK, Kim H, Lee SJ, Chun HK, Lee WY, Yun SH. Deep rectosigmoid endometriosis: "mushroom cap" sign on T2-weighted MR imaging. Abdom Imaging 2010; 35(6): 726-731.

8. Gidwaney R, Badler RL, Yam BL, Hines JJ, Alexeeva V, Donovan V, et al. Endometriosis of Abdominal and Pelvic Wall Scars: Multimodality Imaging Findings, Pathologic Correlation, and Radiologic Mimics. Radiographics 2012; 32(7): 2031-2043. 